\title{
Molecular diversity and population structure of the forage grass Hemarthria compressa (Poaceae) in south China based on SRAP markers
}

\author{
L.-K. Huang, X.-Q. Zhang, W.-G. Xie, J. Zhang, L. Cheng and H.D. Yan \\ Department of Grassland Science, College of Animal Science and Technology, \\ Sichuan Agricultural University, Ya'an, China \\ Corresponding author: X.-Q. Zhang \\ E-mail: zhangxq@sicau.edu.cn
}

Genet. Mol. Res. 11 (3): 2441-2450 (2012)

Received September 16, 2011

Accepted February 27, 2012

Published May 24, 2012

DOI http://dx.doi.org/10.4238/2012.May.24.3

\begin{abstract}
Hemarthria compressa is one of the most important and widely utilized forage crops in south China, owing to its high forage yield and capability of adaptation to hot and humid conditions. We examined the population structure and genetic variation within and among 12 populations of $H$. compressa in south China using sequence-related amplified polymorphism (SRAP) markers. High genetic diversity was found in these samples [percentage polymorphic bands $(\mathrm{PPB})=82.21 \%$, Shannon's diversity index $(\mathrm{I})=0.352]$. However, there was relatively low level of genetic diversity at the population level (PPB $=29.17 \%, \mathrm{I}=$ $0.155)$. A high degree of genetic differentiation among populations was detected based on other measures and molecular markers (Nei's genetic diversity analysis: $G_{\mathrm{ST}}=54.19 \%$; AMOVA analysis: $F_{\mathrm{ST}}=53.35 \%$ ). The SRAP markers were found to be more efficient than ISSR markers for evaluating population diversity. Based on these findings, we propose changes in sampling strategies for appraising and utilizing the genetic resources of this species.
\end{abstract}

Key words: Hemarthria compressa; Genetic diversity; SRAP; Population structure 


\section{INTRODUCTION}

Sequence-related amplified polymorphism (SRAP) technology, developed by Li and Quiros (2001), has been recognized as a new and useful molecular marker system. SRAP is based on twoprimer amplification. The primers are 17 or 18 nucleotides long and consist of a core sequence of 13 to 14 bases long, where the first 10 or 11 bases starting at the 5 '-end are a filler sequence, followed by the sequence CCGG in the forward primer and AATT in the reverse primer. The core sequence is followed by three selective nucleotides at the 3'-end of each primer (Li and Quiros, 2001). As widely used PCR-based markers, SRAP has advantages over other markers. SRAP can produce more reliable and reproducible bands compared to random amplified polymorphic DNA (RAPD), because of the higher annealing temperature and longer primer sequence (Zietkiewicz et al., 1994). Unlike with simple sequence repeats, no prior knowledge of target sequences is required for SRAP. In addition, the cost of SRAP is less than with amplified fragment length polymorphism (AFLP). Up to now, SRAP has been successfully used for the evaluation of genetic diversity (Ferriol et al., 2003; Budak et al., 2004; Comlekcioglu et al., 2010), genetic structure (Wang et al., 2004; Xie et al., 2005; Zhang et al., 2005), and map construction (Lin et al., 2003; Suenaga et al., 2005), among others. There is no report yet about the use of SRAP markers in Hemarthria compressa.

H. compressa (L. f.) R. Br. (whip grass) is a stoloniferous perennial tropical grass of the tribe Andropogonea in the family Poaceae. Whip grass is indigenous to Asian temperate and tropical regions (Chen and Jia, 2002), and it is one of the most important and widely utilized forages in southern China, owing to its forage yield and capability of adaptation to hot and humid conditions. A few studies have been conducted by the Sichuan Agricultural University in the past 50 years, and three cultivars, 'Guang yi', 'Chong gao' and 'Ya an' have been released by the China Forage Registration Committee. 'Guang yi' and 'Chong gao' have been widely used in the Yangtze River and play an important role in animal husbandry and environmental sustenance (Yang et al., 2004). H. compressa can also be used in turf, particularly in low maintenance areas. In high rainfall and sloping areas, it can be used for soil conservation (Yang and Zhang, 2006). H. compressa produces few seeds and has the capacity for clonal growth by rhizomes and stolons ( $\mathrm{Wu}$ and $\mathrm{Du}, 1992)$. In southern China, there are abundant ecotypes of $H$. compressa. The morphologic differentiation and variation in AFLP patterns among the $H$. compressa populations are significant (Chen et al., 2005; Liu et al., 2006). Huang et al. (2008) found that there was strong genetic differentiation among $H$. compressa populations in southern China. Therefore, the objectives of the research were: 1) to check the genetic diversity and genetic structure of $H$. compressa using SRAP, and 2) to compare the efficiency between SRAP and ISSR markers [previous research data (Huang et al., 2008)] in detecting genetic variation within and between populations of $H$. compressa.

\section{MATERIAL AND METHODS}

\section{Plant materials and DNA extraction}

Twelve populations of $H$. compressa were sampled from four provinces, Sichuan (P1-P7), Chongqing (P8, P9), Yunnan (P10), and Guizhou (P11, P12). Twelve or thirteen individuals were collected randomly from each population with a minimum interval of $10 \mathrm{~m}$. A total of 145 samples were used in this study (Table 1). 
Table 1. Geographic information of 12 populations of Hemarthria compressa.

\begin{tabular}{llccc}
\hline Population No. & Origin (County, Province) & Longitude (N) & Latitude (E) & Sample size \\
\hline P1 & Chengdu, Sichuan & $104^{\circ} 36^{\prime}$ & $30^{\circ} 40^{\prime}$ & 12 \\
P2 & Zigong, Sichuan & $104^{\circ} 28^{\prime}$ & $29^{\circ} 14^{\prime}$ & 12 \\
P3 & Hongya, Sichuan & $103^{\circ} 23^{\prime}$ & $29^{\circ} 30^{\prime}$ & 12 \\
P4 & Yaan, Sichuan & $102^{\circ} 59^{\prime}$ & $29^{\circ} 59^{\prime}$ & 13 \\
P5 & Leshan, Sichuan & $103^{\circ} 35^{\prime}$ & $29^{\circ} 45^{\prime}$ & 12 \\
P6 & Mianyang, Sichuan & $104^{\circ} 44^{\prime}$ & $31^{\circ} 30^{\prime}$ & 12 \\
P7 & Ningnan, Sichuan & $102^{\circ} 46^{\prime}$ & $27^{\circ} 04^{\prime}$ & 12 \\
P8 & Chongqing city, Chongqing & $106^{\circ} 32^{\prime}$ & $29^{\circ} 35^{\prime}$ & 12 \\
P9 & Liangping, Chongqing & $107^{\circ} 47^{\prime}$ & $30^{\circ} 40^{\prime}$ & 12 \\
P10 & Qiaojia, Yunnan & $102^{\circ} 55^{\prime}$ & $26^{\circ} 54^{\prime}$ & 12 \\
P11 & Dushan, Guizhou & $107^{\circ} 32^{\prime}$ & $25^{\circ} 50^{\prime}$ & $25^{\circ} 25^{\prime}$ \\
P12 & Libo, Guizhou & $107^{\circ} 53^{\prime}$ & & 12 \\
\hline
\end{tabular}

Total DNA was extracted from approximately $0.5 \mathrm{~g}$ of leaf tissues using a modified CTAB method (Doyle, 1991). The tissues were ground to a fine powder in liquid nitrogen and incubated at $65^{\circ} \mathrm{C}$ for $60 \mathrm{~min}$ in $2 \mathrm{~mL} 2 \mathrm{X} \mathrm{CTAB}$ isolation buffer $[100 \mathrm{mM}$ Tris- $\mathrm{HCl}, \mathrm{pH}$ 8.0, $1.4 \mathrm{M} \mathrm{NaCl}, 20 \mathrm{mM}$ EDTA, 2\% hexadecyltrimethylammonium bromide (CTAB), $2 \%$ $\beta$-mercaptoethanol]. Next, an equal volume of chloroform-isoamyl alcohol (24:1) was added, and tube was mixed by inversion for $10 \mathrm{~min}$ and centrifuged twice. The supernatant was mixed with about $2 \mathrm{~mL}$ ice-cold isopropanol and $1 \mathrm{~mL} 2 \mathrm{M}$ potassium acetate to precipitate the DNA. The DNA was washed twice with $70 \%$ ethanol, air-dried at room temperature and resuspended in about $0.2 \mathrm{~mL} \mathrm{0.1X} \mathrm{TE} \mathrm{buffer} \mathrm{(10} \mathrm{mM} \mathrm{Tris-HCl,} 1 \mathrm{mM}$ EDTA, $\mathrm{pH} 8.0)$. The quality and concentration of the DNA were confirmed by electophoresis on $0.8 \%$ agarose gels by comparing the samples to the standardized lamba DNA size markers.

\section{SRAP-PCR amplification}

Twenty pairs of SRAP primers were used in the present study (Table 2), which were selected from the 228 combinations of 12 forward and 19 reverse primers. The primer sequences were from previous authors' reports (Li and Quiros, 2001; Ferriol et al., 2003; Lin et al., 2003). The protocol for SRAP analysis was based on Li and Quiros (2001). Each 20- $\mu \mathrm{L}$ PCR mixture consisted of 40 ng genomic DNA, $0.2 \mathrm{mM}$ dNTP, 2.5 $\mathrm{mM} \mathrm{MgCl}, 0.5 \mu \mathrm{M}$ primer, $1 \mathrm{X}$ PCR buffer, and $1 \mathrm{U}$ Taq polymerase. Samples were subjected to the following thermal profile: the first five cycles were run at $94^{\circ} \mathrm{C}$ for $1 \mathrm{~min}$, $35^{\circ} \mathrm{C}$ for $1 \mathrm{~min}$, and $72^{\circ} \mathrm{C}$ for $1 \mathrm{~min}$, for denaturing, annealing and extension, respectively. Next, the annealing temperature was raised to $50^{\circ} \mathrm{C}$ for another 35 cycles, followed by another extension step of $10 \mathrm{~min}$ at $72^{\circ} \mathrm{C}$, and then followed by a $4{ }^{\circ} \mathrm{C}$ holding temperature. PCR products were mixed with $5 \mu \mathrm{L}$ loading buffer and separated on $6 \%$ denatured polyacrylamide gels [acrylamide-bisacrylamide (19:1), 0.5X TBE, using DL2000 as DNA marker. The gel was pre-run on $0.5 \mathrm{X}$ TBE buffer at $200 \mathrm{~V}$ constant voltage before the samples were loaded, using DYY-6C electrophoresis equipment. After loading samples, the gel was run at $400 \mathrm{~V}$ constant voltage about 1.5-2 $\mathrm{h}$ until the xylene cyanol had run $2 / 3$ the length of the gel, and the temperature was kept under $50^{\circ} \mathrm{C}$ to avoid breaking the gel-support glass. After electrophoresis, the gel was stained with $\mathrm{AgNO}_{3}$ solution $(\mathrm{Xu}$ et al., 2002), and gels were then photographed. 
Table 2. Primers of SRAP analysis used in this study.

\begin{tabular}{|c|c|c|c|}
\hline Primer & Sequence $\left(5^{\prime}-3^{\prime}\right)$ & Primer & Sequence (5'-3') \\
\hline \multirow[t]{2}{*}{ me1+em6 } & TGAGTCCAAACCGGTTG & me7+em13 & TGAGTCCAAACCGGTCC \\
\hline & GACTGCGTACGAATTGCA & & GACTGCGTACGAATTAGC \\
\hline \multirow[t]{2}{*}{ me1+em8 } & TGAGTCCAAACCGGTTG & $\mathrm{me} 7+\mathrm{em} 16$ & TGAGTCCAAACCGGTCC \\
\hline & GACTGCGTACGAATTCTG & & GACTGCGTACGAATTTCG \\
\hline \multirow[t]{2}{*}{$\mathrm{me} 1+\mathrm{em} 13$} & TGAGTCCAAACCGGTTG & me8+em11 & TGAGTCCAAACCGGTGC \\
\hline & GACTGCGTACGAATTAGC & & GACTGCGTACGAATTCCA \\
\hline \multirow{2}{*}{ me5+em8 } & TGAGTCCAAACCGGAAG & $\mathrm{me} 8+\mathrm{em} 12$ & TGAGTCCAAACCGGTGC \\
\hline & GACTGCGTACGAATTCTG & & GACTGCGTACGAATTATG \\
\hline \multirow[t]{2}{*}{ me5+em 11} & TGAGTCCAAACCGGAAG & me $8+\mathrm{em} 18$ & TGAGTCCAAACCGGTGC \\
\hline & GACTGCGTACGAATTCCA & & GACTGCGTACGAATTGGT \\
\hline \multirow{2}{*}{ me5+em12 } & TGAGTCCAAACCGGAAG & me9+em4 & TGAGTCCAAACCGGTAG \\
\hline & GACTGCGTACGAATTATG & & GACTGCGTACGAATTTGA \\
\hline \multirow[t]{2}{*}{ me5+em16 } & TGAGTCCAAACCGGAAG & me9+em7 & TGAGTCCAAACCGGTAG \\
\hline & GACTGCGTACGAATTTCG & & GACTGCGTACGAATTCAA \\
\hline \multirow[t]{2}{*}{ me6+em 11} & TGAGTCCAAACCGGTAA & me9+em8 & TGAGTCCAAACCGGTAG \\
\hline & GACTGCGTACGAATTCCA & & GACTGCGTACGAATTCTG \\
\hline \multirow[t]{2}{*}{ me6+em 16} & TGAGTCCAAACCGGTAA & me9+em16 & TGAGTCCAAACCGGTAG \\
\hline & GACTGCGTACGAATTTCG & & GACTGCGTACGAATTTCG \\
\hline \multirow[t]{2}{*}{$\mathrm{me} 7+\mathrm{em} 12$} & TGAGTCCAAACCGGTCC & $\mathrm{me} 12+\mathrm{em} 5$ & TGAGTCCAAACCGGTCA \\
\hline & GACTGCGTACGAATTATG & & GACTGCGTACGAATTGAC \\
\hline
\end{tabular}

\section{Data analysis}

Only bands that could be unambiguously scored across all the sampled populations were used in this study. SRAP-amplified fragments, with the same mobility according to the molecular weight (bp), were scored manually for band presence (1) or absence (0). The resulting presence/absence data matrix was analyzed using POPGENE v. 1.31 (Yeh et al., 1999), assuming Hardy-Weinberg equilibrium, to estimate three genetic diversity parameters: the percentage of polymorphic loci (PPB), Shannon's information index of diversity $(I)$ and Nei's gene diversity $(H)$. The coefficient of genetic differentiation $\left(G_{\mathrm{ST}}\right)$ was measured following by Nei (1972); the genetic identity and genetic distance $(G D)$ between populations were also computed using the same program (Nei, 1973). Gene flow estimates $\left(N_{\mathrm{m}}\right)$ were calculated as $N_{\mathrm{m}}=\left(1 / G_{\mathrm{ST}}-1\right) / 4$.

The analysis of molecular variance (AMOVA) was used to partition the total SRAP variation into within-population and between-population (Excoffier et al., 1992). Variance components, the sum of all squared differences, and analogues of F-statistics based on Euclidean distance between individuals were calculated to estimate the population differentiation, which was the equivalent of the Wright $F_{\mathrm{ST}}$ index (Wright, 1965). The input files for AMOVA were prepared by the aid of the DCFA1.1 program written by Zhang (2001). Dendrograms were constructed with a genetic identity matrix to display population relationships using the unweighted pair-group mean algorithm (UPGMA) of NTSYS-pc, version 2.10 (Rohlf, 1997). To test for correlations between genetic distances and geographic distances (in $\mathrm{km}$ ) between the populations, a Mantel test was also performed with NTSYS-pc.

Marker utility is a function of information content per marker and the number of markers generated per assay. In this study, we employed marker index (MI), effective multiplex ratio (EMR), and average band informativeness $\left(\mathrm{Ib}_{\mathrm{av}}\right)$ to compare the marker utility of two markers. Marker index was estimated as MI $=\mathrm{Ib}_{\mathrm{av}} \times$ EMR (Powell and Morgante, 1996). Average band informativeness (Ibav) was employed to estimate the information content per marker. Average band informativeness of a technique, with a range 
from 0 to 1 , was calculated as Ibav $=1 / \mathrm{n} \sum 1-\left(2\left|0.5-\mathrm{p}_{\mathrm{i}}\right|\right)$, where $p_{i}$ is the proportion of accessions containing the ith amplicon and $n$ is the total number of amplicons (Milbourne et al., 1997; Archak et al., 2003).

\section{RESULTS}

\section{Genetic diversity of $H$. compressa}

A summary of the genetic data for between 12 populations and within populations of $H$. compressa is given in Table 3. Among 12 populations, 20 SRAP primers amplified 268 clear and reproducible polymorphic bands (82.21\%). The percentage of polymorphic loci (P) within populations ranged from $8.90 \%$ (P1) to $49.39 \%$ (P8), with an average of $29.17 \%$. The Shannon's diversity index $(I)$ ranged from 0.0408 (P1) to 0.1617 (P8), with an average of 0.155 at the population level, and 0.352 at the species level. The variation trend of Nei's gene diversity $(H)$ was similar to the other two diversity indices (Table 3).

\begin{tabular}{|c|c|c|c|c|c|c|}
\hline & Polymorphic bands & PPB & $H$ & $I$ & $G_{\mathrm{ST}}$ & $N_{\mathrm{m}}$ \\
\hline Between 12 populations & 268 & $82.21 \%$ & 0.227 & 0.352 & $54.19 \%$ & 0.212 \\
\hline Within populations (average) & 95.17 & $29.17 \%$ & 0.104 & 0.155 & & \\
\hline
\end{tabular}

\section{Genetic structure of $H$. compressa}

We found that there was significant differentiation among the populations of $H$. compressa, using the SRAP markers. The coefficient of genetic differentiation between populations $\left(G_{\mathrm{ST}}\right.$, estimated by partitioning of the total gene diversity) was $54.19 \%$, revealed by SRAP. Based on $G_{\mathrm{ST}}$ values, the estimated number of migrants per generation $\left(N_{\mathrm{m}}\right)$ between populations was 0.212 at the species level, revealed by SRAP.

AMOVA of the distance matrix for the 145 individuals permitted a partitioning of the overall variation into two levels, which provided a result similar to the POPGENE results (Table 4). The proportion of variation within population differences was $53.35 \%$ and the remainder occurred between populations.

Table 4. Analysis of molecular variance for 12
\begin{tabular}{lccrccc} 
Source of variation & d.f. & SSD & MSD & Variance component & Total variance (\%) & P values \\
\hline Between populations & 11.00 & 3057.71 & 277.97 & 21.45 & $53.35 \%$ & $<0.001$ \\
Within populations & 133.00 & 2494.49 & 18.76 & 18.75 & $46.65 \%$ & $<0.001$ \\
Total & 144.00 & 5552.20 & & & & \\
\hline
\end{tabular}

d.f. $=$ degrees of freedom; SSD = sum of squared deviations; MSD = mean squared deviation.

Table 5 shows Nei's unbiased measures of genetic distance between 12 populations of H. compressa. The data of SRAP markers revealed that genetic variation between population 2 and population 12 was most significant (0.29), and the average genetic distance was 0.163 . 
Table 5. Nei's (1978) unbiased genetic distance between 12 populations of Hemarthria compressa generated by SRAP.

\begin{tabular}{|c|c|c|c|c|c|c|c|c|c|c|c|c|}
\hline & P1 & P2 & P3 & P4 & P5 & P6 & P7 & P8 & P9 & P10 & P11 & P12 \\
\hline \multicolumn{13}{|l|}{ P1 } \\
\hline P2 & 0.06 & & & & & & & & & & & \\
\hline P3 & 0.05 & 0.08 & & & & & & & & & & \\
\hline P4 & 0.12 & 0.12 & 0.10 & & & & & & & & & \\
\hline P5 & 0.17 & 0.14 & 0.14 & 0.09 & & & & & & & & \\
\hline P6 & 0.15 & 0.15 & 0.13 & 0.11 & 0.10 & & & & & & & \\
\hline P7 & 0.19 & 0.18 & 0.16 & 0.14 & 0.11 & 0.09 & & & & & & \\
\hline P8 & 0.19 & 0.18 & 0.17 & 0.15 & 0.12 & 0.10 & 0.09 & & & & & \\
\hline P9 & 0.25 & 0.23 & 0.23 & 0.20 & 0.17 & 0.17 & 0.17 & 0.07 & & & & \\
\hline P10 & 0.27 & 0.27 & 0.24 & 0.22 & 0.18 & 0.16 & 0.14 & 0.10 & 0.12 & & & \\
\hline P11 & 0.26 & 0.26 & 0.26 & 0.20 & 0.15 & 0.15 & 0.13 & 0.12 & 0.14 & 0.11 & & \\
\hline P12 & 0.28 & 0.29 & 0.28 & 0.24 & 0.22 & 0.16 & 0.17 & 0.16 & 0.20 & 0.15 & 0.08 & \\
\hline
\end{tabular}

\section{Cluster analysis}

A cluster analysis (UPGMA) was used to generate a dendrogram based on the genetic identity of SRAP (Figure 1) between 12 populations. In Figure 1, 12 populations were separated into two main clusters. Cluster 1 comprised all 7 populations (P1 to P7) collected from Sichuan. The others composed the cluster 2. In cluster 2, two populations from Guizhou (P11, P12) and two populations from Chongqing (P8, P9) clustered together. The dendrogram shows some evidence in accordance with geographic distribution of $H$. compress $a$. The correlation coefficient of between genetic distance based on SRAP and geographic distance was poor $(r=0.721)$.

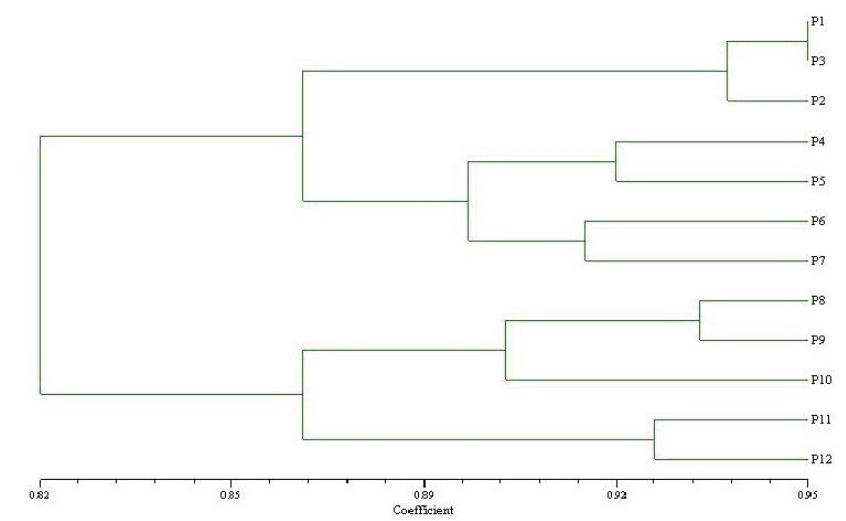

Figure 1. UPGMA-derived dendrogram showing the clustering of the 12 populations of Hermathria compressa based on the genetic identity of Nei (1973).

\section{Comparison of marker utility of ISSR and SRAP}

ISSR and SRAP items about marker utility are given in Table 6. In this study, the ISSR and SRAP surveys between 12 populations of $H$. compressa revealed 86.21 and $82.21 \%$ polymorphic bands, respectively, which showed that the two molecule marker systems had similar discriminating power. Ibav of ISSR and SRAP was similar (0.32 and 
0.34, respectively). However, EMR and the numbers of markers generated by each primer of ISSR (10.42 and 12.08, respectively) were lower than that of SRAP (13.40 and 16.30, respectively). MI, a synthetic index, was used to evaluate the efficiency of different molecule marker systems, which depends upon both the Ibav and number of markers generated by each primer. In this study, MI of SRAP (4.51) was higher than that of ISSR (3.36). Therefore, SRAP was more efficient than ISSR in genetic diversity research of $H$. compressa. The correlation between the matrices of genetic distance values based on ISSR and RAPD data was poor $(\mathrm{r}=0.654)$.

\begin{tabular}{lcc}
\multicolumn{2}{l}{ Table 6. Comparison of usefulness between ISSR and SRAP. } \\
\hline Item & ISSR & SRAP \\
\hline No. of primers & 12.00 & 20.00 \\
No. of total loci & 145.00 & 326.00 \\
No. of average loci per primer & 12.08 & 16.30 \\
Percentage of polymorphic bands (PPB) & $86.21 \%$ & $82.21 \%$ \\
Average band informativeness (Ibav) & 0.32 & 0.34 \\
Effective multiplex ratio (EMR) & 10.42 & 13.40 \\
Marker index (MI) & 3.36 & 4.51 \\
\hline
\end{tabular}

\section{DISCUSSION}

\section{High genetic diversity of $H$. compressa}

In the present study, high genetic diversity was observed by SRAP at the H. compressa species level. This result is similar to that of previous studies on $H$. compressa. At the morphologic level, Cheng et al. (2005) found a rich variation in the morphology of $H$. compressa. The rich genetic diversity $(\mathrm{PPB}=88.60 \%$ ) between populations of $H$. compressa was also revealed using AFLP markers (Liu et al., 2006, Huang et al., 2008). Compared with other clonal plants, such as Psammochloa villosa $(\mathrm{PPB}=70.5 \%)(\mathrm{Li}$ and $\mathrm{Ge}, 2001)$; Monimopetalum chinese $(\mathrm{P}$ $=36.36, I=0.183$ ) (Xie et al., 2005), $H$. compressa harbored richer genetic diversity. There are many reasons for the high genetic diversity in clonal plants, such as reproductive mode, geographic distribution, habit, dispersal, and population history (Xia et al., 2002). As to $H$. compressa, the main reason could be that this species shows habitat diversity and is widely distributed in southern China (Yang et al., 2004; Chen et al., 2005).

\section{Genetic differentiation between populations of $H$. compressa}

In this study, a high level of genetic differentiation was detected by SRAP markers using different approaches $\left(G_{\mathrm{ST}}\right.$ and AMOVA) in $H$. compressa. The result was similar to that of a previous study in $H$. compressa (Huang et al., 2008) and some other clonal plants. Xie et al. (2005) revealed strong genetic differentiation between populations $\left(G_{\mathrm{ST}}=49.06 \%\right)$ in $M$. chinense. Han et al. (2007) found $50.47 \%$ (based on AMOVA) of the genetic diversity residing between populations of Nelumbo nucifera, an aquatic plant, using ISSR markers. The high differentiation of $H$. compressa may be ascribed to its reproduction system. $H$. compressa produces few seeds because of low rates of seed bearing and seed germination (Wu and $\mathrm{Du}$, 2000; Yang et al., 2004), and reproduces mainly through its rhizomes and stolons. As to such 
kind of species, the main resource of low gene flow is water and animals (Wu and $\mathrm{Du}, 1992)$, and the estimated gene flow of $H$. compressa $\left(N_{\mathrm{m}}=0.264\right)$ is low. The levels of gene flow calculated here are of insufficient magnitude to counter-balance genetic drift, which may also play a role in the population differentiation observed. Lack of effective mechanisms for longdistance dispersal of genetic materials may also play an important role in shaping the genetic structure observed (Wallace, 2002). Furthermore, habitat fragment caused by human action also contributes to genetic differentiation. The high degree of genetic differentiation between populations of $H$. compressa may be one reason for the poor correlations between geographic distance and genetic distance generated from different marker techniques.

\section{Comparison of ISSR and SRAP data}

In this study, although, ISSR and SRAP had the great and similar discriminating power and could accurately detect the partition of genetic diversity within and between populations of $H$. compressa, SRAP showed more advantages than ISSR. First, SRAP was more efficient than ISSR in genetic diversity research of $H$. compressa, for the MI of SRAP (4.51) was higher than that of ISSR (3.36). The great efficiency was mainly ascribed to more bands amplified per primer. Furthermore, SRAP resolved more genetic differentiation between 12 populations of $H$. compressa because of the $G_{\mathrm{ST}}$ and AMOVA detected by ISSR and SRAP. Additionally, the correlation coefficient between genetic distance based on SRAP and geograhpic distance was higher than that of ISSR. Lastly, the dendrogram of SRAP showed some evidence in accordance with the geographic distribution of $H$. compressa, but the dendrogram of ISSR did not. Therefore, as a novel molecule marker, SRAP has great potential in genetic diversity research of $H$. compressa.

In the present study, the correlation between genetic distance values generated from different marker techniques was poor $(\mathrm{r}=0.654)$, and clustering of populations within groups was not very similar when ISSR- and SRAP-derived dendrograms were compared. These differences may be explained by the following. 1) Different DNA segments are targeted by the two methods. The inter-simple sequence repeats are regions lying within the microsatellite repeats, while the target locus of SRAP are mainly in open reading frame regions (Zietkiewicz et al., 1994; Li and Quiros, 2001). 2) Genomic regions sampled by the ISSR and SRAP markers maintain a different evolutionary process under selection. 3) Numbers of loci studied and their coverage of the overall genome are important in obtaining reliable estimates of genetic relationships between populations and within population (Loarce et al., 1993).

\section{CONCLUSION}

As two dominant DNA markers, ISSR and SRAP are promising marker systems for detecting genetic variation. Furthermore, SRAP is superior to ISSR in terms of its efficiency and the reproducibility.

A better understanding of the extent and patterns of genetic diversity of H. compressa in southern China is essential for its conservation and utilization. It will help us in determining the strategy for the protecting and sampling management of $H$. compressa. The results from this study show that there is a high level of genetic diversity between populations but a low level genetic variation within population. Thus, when we are sampling plant breeding materials, we should sample as many populations as possible to get enough diversity of $H$. compressa. 


\section{ACKNOWLEDGMENTS}

Research supported by the National Science \& Technology Pillar Program in the Twelfth Five-Year Plan (\#2011BAD17B03), the earmarked fund for Modern Agro-Industry Technology Research System (\#CARS-35-05) and the founding of Ministry of Science and Technology on the commercialization of research findings (\#2010GB2F000402) We thank Yi Yangjie and Li Fang for laboratory assistance.

\section{REFERENCES}

Archak S, Gaikwad AB, Gautam D, Rao EV, et al. (2003). Comparative assessment of DNA fingerprinting techniques (RAPD, ISSR and AFLP) for genetic analysis of cashew (Anacardium occidentale L.) accessions of India. Genome 46: 362-369.

Budak H, Shearman RC, Parmaksiz I and Dweikat I (2004). Comparative analysis of seeded and vegetative biotype buffalograsses based on phylogenetic relationship using ISSRs, SSRs, RAPDs, and SRAPs. Theor. Appl. Genet. 109: $280-288$.

Chen MJ and Jia SX (2002). Chinese Feeding Plant. Chinese Agricultural Press, Beijing, 401-402.

Chen YX, Zhang XQ, Yang CH, Ma X, et al. (2005). The study on morphologic diversity of wild Hemarhria compressa from southwest China. Grassland China 27: 77-79.

Comlekcioglu N, Simsek O, Boncuk M and Aka-Kacar Y (2010). Genetic characterization of heat tolerant tomato (Solanum lycopersicon) genotypes by SRAP and RAPD markers. Genet. Mol. Res. 9: 2263-2274.

Doyle J (1991). DNA Protocols for Plants-CTAB Total DNA Isolation. In: Molecular Techniques in Taxonomy (Hewitt GM and Johnston A, eds.). Springer, Berlin, 283-293.

Excoffier L, Smouse PE and Quattro JM (1992). Analysis of molecular variance inferred from metric distances among DNA haplotypes: application to human mitochondrial DNA restriction data. Genetics 131: 479-491.

Ferriol M, Pico B and Nuez F (2003). Genetic diversity of a germplasm collection of Cucurbita pepo using SRAP and AFLP markers. Theor. Appl. Genet. 107: 271-282.

Han YC, Teng CZ, Zhong S, Zhou MQ, et al. (2007). Genetic variation and clonal diversity in populations of Nelumbo nucifera (Nelumbonaceae) in central China detected by ISSR markers. Aquat. Bot. 86: 69-75.

$\mathrm{Li}$ A and Ge S (2001). Genetic variation and clonal diversity of Psammochloa villosa (Poaceae) detected by ISSR markers. Ann. Bot. 87: 585-590.

Li G and Quiros CF (2001). Sequence-related amplified polymorphism (SRAP), a new marker system based on a simple PCR reaction: Its application to mapping and gene tagging in Brassica. Theor. Appl. Genet. 103: 455-461.

Lin ZX, Zhang XL and Nie YC (2003). Construction of a genetic linkage map for cotton based on SRAP. Chin. Sci. Bull. 48: 2063-2068.

Liu JP, Zhang XQ, Peng Y, Yang CH, et al. (2006). AFLP analysis about genetic diversity of Hemarthria compressa in southwest region of China. J. Anhui Agric. Sci. 12: 46-47.

Loarce Y, Gallego R and Ferrer E (1993). A comparative analysis of genetic relationships between rye cultivars using RFLP and RAPD markers. Euphytic 88: 107-115.

Milbourne D, Rbonda M, Bradsbaw E, Baird E, et al. (1997). Comparison of PCR-based marker systems for the analysis of genetic relationships in cultivated potato. Mol. Breed. 3: 127-136.

Nei M (1972). Genetic distance between populations. Am. Nat. 106: 282-292.

Nei M (1973). Analysis of gene diversity in subdivided populations. Proc. Natl. Acad. Sci. U. S. A. 70: 3321-3323.

Powell W and Morgante M (1996). The comparison of RFLP, RAPD, AFLP and SSR (microsatellite) markers for germplasm analysis. Mol. Breed. 2: 225-238.

Rohlf FJ (1997). NTSYS-pc, Numerical Taxonomy and Multivariate Analysis System, Version 2.1. Applied Biostatistics Inc., New York.

Suenaga K, Khairallah M, William HM and Hoisington DA (2005). A new intervarietal linkage map and its application for quantitative trait locus analysis of "gigas" features in bread wheat. Genome 48: 65-75.

Wallace LE (2002). Examining the effects of fragmentation on genetic variation in Platanthera leucophaea (Orchidaceae): inferences from allozyme and random amplified polymorphic DNA markers. Plant Spec. Biol. 17: 37-49.

Wang CN, Moller M and Cronk QC (2004). Population genetic structure of Titanotrichum oldhamii (Gesneriaceae), a subtropical bulbiliferous plant with mixed sexual and asexual reproduction. Ann. Bot. 93: 201-209.

Genetics and Molecular Research 11 (3): 2441-2450 (2012) 
Wright S (1965). The interpretation of population structure by F-statistics with special regard to systems of mating. Evolution 19: 395-420.

Wu YQ and Du Y (1992). Research of limpograsses (Hemarhria compressa) as forage. J. Sic. Agr. Univ. 10: 260-265.

Wu YQ and Du Y (2000). Some reproductive characteristics of Hemarhria compressa. J. Sic. Agr. Univ. 18: 262-264.

Xia LQ, Li JQ and Li W (2002). Genetic diversity of clonal plant. Chin. Bull. Bot. 19: 425-431.

Xie GW, Wang DL, Yuan YM and Ge XJ (2005). Population genetic structure of Monimopetalum chinense (Celastraceae), an endangered endemic species of eastern China. Ann. Bot. 95: 773-777.

Xu SB, Tao YF, Yang ZQ and Chu JY (2002). A simple and rapid methods used for silver staining and gel preservation. Yi Chuan 24: 335-336.

Yang CH and Zhang XQ (2006). Hemarhria compressa: growth behavior and multipurpose. Acta Pratculturae Sin. 15: 246-248.

Yang CH, Zhang XQ and Li XL (2004). Hemarhria germplasm resources and breeding. Acta Pratculturae Sin. 13: 7-12.

Yeh FC, Yang RC and Boyle T (1999). POPGENE VERSION 1.32. Microsoft Windows-Based Freeware for Population Genetic Analysis. Quick User Guide. University of Alberta: Center for International Forestry Research, Edmonton.

Zhang FM (2001). DCFA1.1, A Program Accompanied by AMOVA to Compute the Matrix of Distance. Laboratory of Systematic and Evolutionary Botany, Institute of Botany, The Chinese Academy of Science, Beijing.

Zhang J, Fernando WG and Remphrey WR (2005). Genetic diversity and structure of the Apiosporina morbosa populations on Prunus spp. Phytopathology 95: 859-866.

Zietkiewicz E, Rafalski A and Labuda D (1994). Genome fingerprinting by simple sequence repeat (SSR)-anchored polymerase chain reaction amplification. Genomics 20: 176-183. 